\title{
Interaction of Nitric Oxide with Phytohormones under Drought Stress
}

\author{
Srivani S. Adimulam ${ }^{1}$, Bhatnagar-Mathur Pooja ${ }^{1} \&$ Santisree Parankusam ${ }^{1}$ \\ ${ }^{1}$ International Crops Research Institute for the Semi-Arid Tropics (ICRISAT), Patancheru, Hyderabad-502324, \\ Andhra Pradesh, India \\ Correspondence: Santisree Parankusam, Research Program on Grain Legumes, International Crops \\ ResearchInstitute for the Semi-Arid Tropics (ICRISAT), Patancheru, Hyderabad-502 324, Andhra Pradesh, \\ INDIA. Tel: 91-403-071-300. E-mail: S.Parankusam@cgiar.org
}

Received: December 9, 2016

Accepted: January 4, 2017 Online Published: January 21, 2017

doi:10.5539/jps.v6n1p58

URL: http://dx.doi.org/10.5539/jps.v6n1p58

\begin{abstract}
Plants are often exposed to a plethora of stress conditions such as salinity, extreme temperatures, drought, and heavy metals that can greatly impact farmer's income. Nitric oxide (NO) has been implicated in resistance to various plant stresses and hence gaining increasing attention from plant researchers. NO mediate various abiotic and biotic stresses in plants including drought stress. However, it is still unclear about the actual involvement of NO in drought stress responses at a whole plant level. Whether NO act alone or in coherence with other phytohormones and signaling molecules is an open question till now. Here we summarized the interaction of NO with the well-known phytohormones in coping with the drought stress.
\end{abstract}

Keywords: nitric oxide (NO), drought stress, phytohormones, auxin, abscisic acid, abiotic stress

Being highly reactive, nitric oxide involves interactions with various signaling pathways to execute cell-, tissueor organelle-specific roles in plants (Simontacchi et al., 2013; Freschi, 2013). After a series of experimental reports in the recent decade, the participation of NO in plant hormone mediated responses was highlighted by various research groups (Freschi, 2013). Nitric oxide interaction with phytohormones in drought stress can be broadly in three ways:

1) $\mathrm{NO}$ and phytohormones mutually get induced under drought stress.

2) NO gets recruited by plant hormones under stress condition.

3) NO acts as a cross talk node for interacting hormones.

A majority of the research publications highlighted the interaction between ABA and NO during drought stress conditions. An intensive synergistic and antagonistic cross talks has been described between NO and ABA depending on the physiological response and tissue during drought stress (Freschi, 2013; Santisree et al., 2015). Garcia-Mata and Lamattina (2001) suggested that NO was a part of ABA signaling pathways during drought induced stomatal closure in Vicia fava epidermal trips. The synergistic relation between NO and ABA was also reported during some responses like stomatal closure as in Arabidopsis thaliana and Pisum sativum (Neill et al., 2008). NO and ABA share many signaling components like cGMP, Ca2+, cADPR, and G proteins during drought stress (Xing et al., 2004). For instance, in $V . f a b a$ guard cells, NO is involved in the ABA induced stomatal closure by selectively activating intracellular $\mathrm{Ca} 2+$ channels through a cGMP/cADPR-dependent signaling pathway (Mioto, \& Mercier, 2013). Furthermore, NO and ABA are mutually regulated under drought stress. For example, NO via NOS like activity induce ABA accumulation in wheat root tips under drought stress. In corn, elevation of NADPH by ABA led to the production of NO, proving the functional relationship between $\mathrm{ABA}$ and NO during drought stress. Another well-known response of ABA and NO interaction is the induction of antioxidant defenses under drought-induced oxidative stress in plants (Zhang et al., 2007; Lu et al., 2009). ROS and NO are implicated as co-signaling molecules acts by stimulating ABA synthesis during maintenance of plant water status under drought stress (Bright et al., 2006; Hancock et al., 2011; Desikan et al., 2004). Despite these reports, NO and ABA also known to act antagonistically by counteracting each other's effects in some cases such as seed dormancy breaking during drought stress (Bethke et al., 2006; Liu et al., 2011; Liu et al., 2010).

The interaction between cytokinins and NO during the regulation of plant drought responses has also been studied recently. Shao et al. (2010) reported increased NO levels during the cytokinin-induced photosynthetic 
adaptability to drought stress suggesting an antisenescence role of NO. This study described the possible synergistic relation between cytokinin-induced photosynthestic adaptability and NR-generated NO production in response to drought stress. Synergistic interaction between cytokinins and NO was also reported previously during the control of leaf senescence, programmed cell death, cell division, and differentiation (Shen et al., 2012; Simontacchi et al., 2013).

Auxin is known to regulate a number of plant growth processes in association with NO. For instance, root growth and iron uptake stimulation are the two well-studied auxin regulated responses that operate by mediation of endogenous NO (Simontacchi et al., 2013; Yadav et al., 2011; Liao et al., 2011). Recent pharmacological and mutant analysis studies infer that $\mathrm{NO}$ acts downstream of auxin through a direct signaling pathway during root growth and development with close cooperation with molecules like cGMP (Negi et al., 2010; Liao et al., 2011; Fernandez-Marcos et al., 2011; Li et al., 2013). Increased NO production has been observed by auxin over producing mutants and after exogenous application (Negi et al., 2010; Simontacchi et al., 2013; Kolbert et al., 2008). Kolbert et al. (2008) reported nitrate reductase derived NO accumulation in Arabidopsis root primordia when treated with auxin exogenously. Noteworthy, NO was proven to influence auxin content in plants by modulating auxin synthesis, transport and degradation (Fernandez-Marcos et al., 2011; Xu et al., 2010). Recently some of the transporters were shown to play a major role during drought stress (Remy et al., 2013). However a direct link showing NO mediated modulation of auxin transport or synthesis under drought stress needs further study.

In most of the cases, an antagonisticinteraction was reported between ethylene and NO (Freschi, 2013). Both exogenous and endogenous NO levels can influence ethylene biosynthesis during senescence in plants (Freschi, 2013; Manjunatha et al., 2012). A report in Arabidopsis showed that NO down regulates ethylene precursor S-adenosylmethionine (SAM) levels through S-nitrosylation of methionine adenosyltransferase (MAT1) (Lindermayr et al., 2005). This kind of negative relation is also observed during stomatal closure, where ethylene inhibited stomatal closure when combined with either ABA or NO (Desikan et al., 2006). Similarly, a negative correlation between both of these gases was also reported during fruit ripening (Freschi, 2013; Manjunatha et al., 2012). By contrast, NO is shown to stimulate ethylene production by up regulating the ethylene biosynthesis genes in Arabidopsis and cucumber, while ethylene precursor promoted NO production in senescing leaves (Manjunatha et al., 2012). Similar to ethylene, a general antagonism was documented between Gibberellic acid (GA) and NO during root growth and photomorphogenesis in Arabidopsis (Freschi, 2013; Leon et al., 2011). DELLA proteins known to operate as key molecules in the crossroads of NO and GA signaling pathways (Hui et al., 2009). GA negatively regulated NO production, by promoting DELLA protein accumulation. Indeed, it is clear that cross talk between auxin, GA and ethylene with NO was not studied much under drought stress. Besides its regulation of plant hormone biosynthesis and sensitivity, NO also appears to be involved in modulation of various enzymes of nitrogen metabolism under drought stress (Hui et al., 2009). In addition to major plant hormones, NO has been known to interact with other signaling molecules like salicylic acid (SA), jasmonic acid, polyamines, calcium, ROS and other kinases corroborating its versatile role during various stress conditions (Misra et al., 2011; Freschi, 2013; Simontacchi et al., 2013). Although, now we can evidently show the potential involvement of NO in hormone mediated pathways, the cross talk study is fragmental under individual stress conditions like drought stress. Moreover, the integration of these rudimentary signaling events with respect to individual stress responses is very important to understand how this single molecule modulates other signaling molecules/hormones to elicit specific and common stress responses.

\section{Acknowledgments}

This work was supported by a financial grant to PS through the INSPIRE Faculty Award (IFA12-LSPA-08) from the Department of Science and Technology, Government of India, and partial funding from the CGIAR Research Program on Grain Legumes.

\section{References}

Bethke, P. C., Libourel, I. G., Reinöhl V., \& Jones R. L. (2006). Sodium Nitroprusside, Cyanide, Nitrite, and Nitrate Break Arabidopsis Seed Dormancy in a Nitric Oxide-Dependent Manner. Planta, 223, 805-812. http://dx.doi.org/10.1007/s00425-005-0116-9

Bright, J., Desikan, R., Hancock, J. T., Weir, I. S., \& Neill, S. J. (2006). ABA-Induced NO Generation and Stomatal Closure in Arabidopsis are Dependent on $\mathrm{H}_{2} \mathrm{O}_{2}$ Synthesis. Plant J, 45, 113-122. http://dx.doi.org/10.1111/j.1365-313X.2005.02615.x

Desikan, R., Cheung, M. K., Bright, J., Henso, D., Hancoc, J. T., \& Neill, S. J. (2004). ABA, Hydrogen Peroxide and Nitric Oxide signaling in Stomatal Guard Cells. J. Exp. Bot, 55, 205-212. 
http://dx.doi.org/10.1093/jxb/erh033

Fernandez-Marcos, M., Sanz Lewis, D. R., Muday, G. K., \& Lorenzo, O. (2011). Nitric Oxide Causes Root Apical Meristem Defects and Growth Inhibition While Reducing PIN-FORMED 1 (PIN1)-Dependent AcropetalAuxin Transport. Proc Natl Acad Sci USA, 108, 18506-18511. http://dx.doi.org/10.1073/pnas.1108644108

Freschi, L. (2013). Nitric Oxide and Phytohormone Interactions: Current Status and Perspectives. Front Plant Sci, 4, 398. http://dx.doi.org/10.3389/fpls.2013.00398

Garcia-Mata., \& Lamattina, L. (2001). Nitric Oxide Induces Stomatal Closure and Enhances the Adaptive Plant Responses against Drought Stress. Plant Physiol, 126, 1196-1204. http://dx.doi.org/10.1104/pp.126.3.1196

Hancock, J. T., Neill, S. J., \& Wilson, I. D. (2011). Nitric Oxide and ABA in the Control of Plant Function. Plant Sci,181, 555-559. http://dx.doi.org/10.1016/j.plantsci.2011.03.017

Hui, C., Xiao-wei, W., Yan-mei, Z., \& Huai-rui, S. (2009). Effects of Exogenous Nitric Oxide on the Several Enzymes of Nitrogen Metabolism in MalusHupehensis (Pamp.) Rehd. Seedlings Under Water Stress. Acta Hort Sinica, 36, 781-786.http://yyxb.periodicals.net.cn/defaul.

Kolbert, Z., Bartha, B., \& Erdei, L. (2008). Exogenous Auxin-Induced NO Synthesis is Nitrate Reductase-Associated in Arabidopsis Thaliana Root Primordial. J Plant Physiol, 165, 967-975. http://dx.doi.org/10.1016/j.jplph.2007.07.019

Lu, S. Y., Su, W., Li, H. H., \& Guo, Z. F. (2009). Abscisic Acid Improves Drought Tolerance of Triploid Bermudagrass and Involves $\mathrm{H}_{2} \mathrm{O}_{2}$ - and NO-Induced Antioxidant Enzyme Activities. Plant Physiol Biochem, 47, 132-138. http://dx.doi.org/10.1016/j.plaphy.2008.10.006

Liao, W. B., Huang, G. B., Yu, J. H., Zhang, M. L., \& Shi, X. L. (2011). Nitric Oxide and Hydrogen Peroxide are Involved in Indole-3-Butyric Acid-Induced Adventitious Root Development in Marigold. J Hort Sci Biotechnol, 86, 159-165. http://dx.doi.org/10.1080/14620316.2011.11512742

Lindermayr, C., Saalbach, G., \& Durner, J. (2005). Proteomic Identification of S-Nitrosylated Proteins in Arabidopsis. Plant Physiol, 137, 921-930. http://dx.doi.org/10.1104/pp.104.058719

Leon, J., \& Lozano-Juste, J. (2011). Nitric Oxide Regulates DELLA Content and PIF Expression to Promote Photomorphogenesis in Arabidopsis. Plant Physiol, 156, 1410-1423. http://dx.doi.org/10.1104/pp.111.177741

Liu, X., Deng, Z., Cheng, H., He, X., \& Song, S. (2011). Nitrite, Sodium Nitroprusside, Potassium Ferricyanide and Hydrogen Peroxide Release Dormancy of Amaranthus retroflexus Seeds in a Nitric Oxide-Dependent Manner. Plant Growth Regul, 64, 155-161. http://dx.doi.org/10.1007/s10725-010-9551-0

Liu, Y., Xu, S., Ling, T., Xu, L., \& Shen, W. (2010). Heme Oxygenase/Carbon Monoxide System Participates in Regulating Wheat Seed Germination Under Osmotic Stress Involving the Nitric Oxide Pathway. J Plant Physiol, 167, 1371-1379. http://dx.doi.org/10.1016/j.jplph.2010.05.021

Li, J. S., \& Jia, H. L. (2013). cGMP Modulates Arabidopsis Lateral Root Formation Through Regulation of Polar Auxin Transport. Plant Physiol Biochem, 66, 105-117. http://dx.doi.org/10.1016/j.plaphy.2013.02.014

Manjunatha, G., Gupta, K. J., Lokesh, V., Mur, L. A., \& Neelwarne, B. (2012). Nitric Oxide Counters Ethylene Effects on Ripening Fruits. Plant Signal Behav, 7, 476-483. http://dx.doi.org/10.4161/psb.19523

Mioto, P. T., \& Mercier, H. (2013). Abscisic Acid and Nitric Oxide Signaling in Two Different Portions of Detached Leaves of Guzmania monostachia with CAM up-Regulated by Drought. J Plant Physiol, 170, 996-1002.http://dx.doi.org/10.1016/j.jplph.2013.02.004

Misra, A. N., Misra, M., \& Singh, R. (2011). Nitric Oxide Ameliorates Stress Responses in Plants. Plant Soil Environ, 57, 95-100. http://dx.doi.org/10.1007/978-3-319-17804-2_2

Negi, S., Santisree, P., Kharshiing E. V., \& Sharma, R. (2010). Inhibition of the Ubiquitin-Proteasome Pathway Alters Cellular Levels of Nitric Oxide in Tomato Seedlings. Mol. Plant 3, 854-869. http://dx.doi.org/10.1093/mp/ssq033

Neill, S. J., Desikan, R., Clarke, A., \& Hancock, J. T. (2002). Nitric Oxide is a Novel Component of Abscisic Acid Signaling in Stomatal Guard cells. Plant Physiol, 128, 13-16. http://dx.doi.org/10.1104/pp.010707.

Remy, E., Cabrito, T. R., Baster, P., Batista, R. A., Teixeira, M. C., Friml, J., Sá-Correia, I., \& Duque, P. (2013). 
A Major Facilitator Super family Transporter Plays a Dual Role in Polar Auxin Transport and Drought Stress Tolerance in Arabidopsis. Plant Cell, 25, 901-926. http://dx.doi.org/10.1105/tpc.113.110353

Santisree, P., Bhatnagar-Mathur, P., \& Sharma, K. K. (2015). NO to Drought-Multifunctional Role of Nitric Oxide in Plant Drought: Do We Have All the Answers?. Plant Science, 239, 44-55. http://dx.doi.org/10.1016/j.plantsci.2015.07.012

Shao, R., Wang, K., \& Shangguan, Z. (2010). Cytokinin-Induced Photosynthetic Adaptability of Zea Mays L. to Drought Stress Associated with Nitric Oxide Signal: Probed by ESR Spectroscopy and Fast OJIP Fluorescence Rise. J Plant Physiol, 167, 472-479. http://dx.doi.org/10.1016/j.jplph.2009.10.020

Shen, Q., Wang, Y. T., Tian, H., \& Guo, F. Q. (2012). Nitric Oxide Mediates Cytokinin Functions in Cell Proliferation and Meristem Maintenance in Arabidopsis. Mol. Plant, 6, 1214-25. http://dx.doi.org/10.1093/mp/sss148

Simontacchi,M., Garcia-Mata, C., Bartoli, C. G., Santa-María, G. E., \& Lamattina, L. (2013). Nitric Oxide as a Key Component in Hormone-Regulated Processes. Plant Cell Rep, 32, 853-866. http://dx.doi.org/10.1007/s00299-013-1434-1

Xing, H., Tan, L., An, L., Zhao, Z., Wang, S., \& Zhang, C. (2004). Evidence for the Involvement of Nitric Oxide and Reactive Oxygen Species in Osmotic Stress Tolerance of Wheat Seedlings: Inverse Correlation Between Leaf Abscisic Acid Accumulation and Leaf Water Loss. Plant Growth Reg, 42, 61-68. http://dx.doi.org/10.1023/B:GROW.0000014894.48683.1b

Xu, J., Wang, W., Yin, H., Liu, X., Sun, H., \& Mi, Q. (2010). Exogenous Nitric Oxide Improves Antioxidative Capacity and Reduces Auxin Degradation in Roots of Medicago truncatula Seedlings under Cadmium Stress. Plant Soil, 326, 321-330. http://dx.doi.org/10.1007/s11104-009-0011-4

Yadav, S., David, A., \& Bhatla, S. C. (2011). Nitric Oxide Accumulation and Actin Distribution DuringAuxin-Induced Adventitious Root Development in Sunflower. Sci Hortic, 129, 159-166. http://dx.doi.org/10.1016/j.scienta.2011.03.030

Zhang, F., Wang, Y., Yang, Y., Wu, H., Wang, Di, \& Liu, J. (2007). Involvement of Hydrogen Peroxide and Nitric Oxide in Salt Resistance in the Calluses from Populus euphratica. Plant Cell Environ, 30, 775-785. http://dx.doi.org/10.1111/j.1365-3040.2007.01667.x

\section{Copyrights}

Copyright for this articleis retained by the author(s), with first publication rights granted to the journal.

This is an open-access article distributed under the terms and conditions of the CreativeCommons Attribution license (http://creativecommons.org/licenses/by/4.0/). 